\title{
Vortex cosmiques dans l'éternité
}

\section{Christina Aus der Au}

Prof. de théologie, membre de la rédaction Ethique

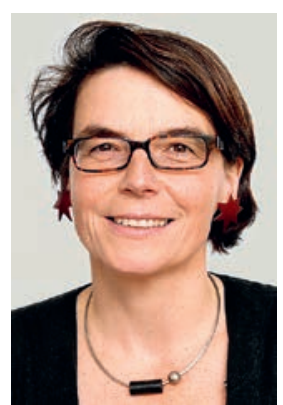

J'étais assise avec d'autres sur la terrasse de l'auberge de jeunesse. Nous avions derrière nous une journée intense. Nous étions venus de différents pays pour un atelier, avions échangé des savoirs et des expériences, présenté des PowerPoint, discuté, organisé, planifié.

A présent, c'était le soir, une chaude soirée d'été, nous étions assis dehors et mon voisin hongrois partageait sa bouteille de vin avec moi. Le monde était parfait. Un Français a tiré un paquet de cigarillos de sa poche. Ceux avec du tabac à pipe, que je fumais aussi de temps en temps dans ma jeunesse. Et là, ça me prend. «Est-ce que je peux t'en piquer un?» Il me tend son paquet et je me sers. L'allume à l'allumette qu'il me présente. J'aspire, sans avaler la fumée, mais je sens son goût contre mon palais, je la garde en bouche avant de l'expirer lentement. Je souris aux visages étonnés qui m’entourent. J'envoie des ronds de fumée dans l'air nocturne. Le monde est parfait.

Le lendemain matin, quand je me réveille, je sens non seulement la courte nuit, mais surtout la fumée froide dans ma gorge. Beurk, c'est encore pire que d'avoir mangé de l'ail la veille. Qu'est-ce qui m'a prise hier soir? Je suis vraiment trop vieille pour me mettre tout à coup à fumer. Je n'ai plus besoin d'avoir l'air cool, ni de prouver que je fais partie d'un groupe quelconque. Je n'ai pas besoin d'une clope pour occuper mes mains ou pour entrer en conversation avec les autres. Fumer est cher et malsain jusqu'à la stupidité.

Mais là, c'était juste chouette. A sa place. Nous avions auparavant parlé de Dieu et du monde, de l'Église et de la société, en Pologne, en Roumanie, en Hongrie, en Angleterre, aux Etats-Unis. Du réchauffement climatique et des migrations, du fossé qui se creuse entre les pauvres et les riches. Tout est lié, et que pouvons-nous y faire? Et pourtant, nous aimerions faire quelque chose, nous unir, renforcer la société civile européenne, continuer à dialoguer par-delà les frontières. Mais c'est sacrément difficile et complexe.

C'est pourquoi nous essayons au moins de faire quelque chose dans notre propre vie, à défaut de changer le monde. Certains de mes amis sont devenus végétaliens. Plus de produits animaux, plus de lait, plus d'œufs, plus de cuir. Pour des raisons valables, santé, écologie, réchauffement climatique, souffrance animale. Les arguments contre sont l'agriculture régionale, notre culture, les produits importés. Et la santé, disent les autres. Alors il faut au moins s'orienter vers le bio, le commerce équitable, les productions régionales. Mais est-ce qu'on doit être libres de le choisir ou est-ce qu'il faut légiférer dans ce sens? Et le sujet redevient immédiatement très complexe.

C'est là que mon collègue a sorti ses cigarillos. Un instant merveilleusement simple, délicieusement dépourvu de sens, où «le présent est le présent». Passé, présent et futur ronronnent ensemble. Nous. Ici. Maintenant. C'est chouette.

Pouvoir s'arroger un moment comme celui-là de temps à autre, est à mon sens, ce qui nous protège, ou du moins ce qui me protège du surmenage et du débordement intellectuel et émotionnel. J'ai mis au point quelques petites et grandes stratégies pour décrocher ainsi: sortir brièvement dans le jardin, boire un thé, caresser le chat, jouer au solitaire... Toutes ces choses qui permettent de repousser un peu les tâches sérieuses et complexes. Bien souvent, ce n'est rien d'autre que de la procrastination, pour employer le terme technique désormais en vogue. Plus tard, demain, tout sauf aujourd'hui... et puis on revient et rien n'a changé sauf que la date limite est un peu plus proche qu'avant.

Et parfois, un tel moment est aussi bien plus. Parfois, cet instant nous permet de glisser dans l'éternité comme à travers un vortex cosmique. Les contraires disparaissent dans la réalité vécue: étranger/familier, simple/complexe, bien/mal, passé/futur. Les choses sont ce qu'elles sont, dit le moment.

Mais ce n'est pas complètement sans danger - notamment lorsqu'il risque d'y avoir des répercussions à long terme. L'ivresse de la vitesse. La consommation de drogue. L'infidélité. Des expériences qui s'accompagnent sans doute aussi de cet exaltant sentiment d'éternité. A côté, mon cigarillo était bien inoffensif. Le lendemain soir, j'ai voulu recommencer. Mon collègue m'en a à nouveau proposé un. Je l'ai allumé, j’ai inspiré, expiré. C'était sympa, mais à des années-lumière de l'expérience métaphysique de la veille. Les vortex cosmiques ne s'ouvrent pas à la demande. 